\title{
LA CADUCIDAD EN LAS LEYES PROVINCIALES DE ADHESION A LA LEY 27.348
}

\begin{abstract}
Ana María Salas ${ }^{1}$
Sumario: I.- Nociones preliminares. II.- La caducidad en el Código Civil y Comercial. III.- La caducidad en las leyes provinciales de adhesión a la ley 27.348. IV.- Argumentos que ponen en crisis los plazos de caducidad de las legislaciones provinciales. V.- La conclusión final que genera el tema.
\end{abstract}

Resumen: La ley 27.348 invitó a las provincias y a la Ciudad Autónoma de Buenos Aires a adherir a las disposiciones contenida en el Título I de la ley (art. 4) . Esa adhesión importó la obligatoriedad de la intervención de las comisiones médicas jurisdiccionales con carácter previo y excluyente. Por ello los trabajadores deben necesariamente solicitar la definición de esos organismos del carácter profesional de su enfermedad o contingencia, la determinación de su incapacidad y las correspondientes prestaciones dinerarias previstas en la Ley de Riesgos del Trabajo.

Algunas provincias al dictar las leyes de adhesión establecieron un plazo de caducidad para acceder a la instancia judicial. El análisis de esa caducidad es lo que se propone realizar en el presente trabajo con el objeto de verificar la compatibilidad del instituto con la Constitución Nacional y tratados internacionales que integran el Bloque de Constitucionalidad Federal (art. 75, inc. 22 de la CN).

Palabras clave: Caducidad. Plazo. Inconstitucionalidad. Inconvencionalidad. Adhesión

\section{I.- Nociones preliminares}

El instituto de la caducidad pone en debate la importancia que tiene el tiempo en el derecho y las dificultades que generan las regulaciones que tratan la temática, sobre todo cuando a través de las mismas se define el nacimiento o la extinción de derechos.

Corresponde advertir que la caducidad que será tratada es la de naturaleza exclusivamente sustancial. Queda fuera toda referencia a la caducidad de naturaleza procesal, aún cuando en alguna parte del estudio se haga referencia a disposiciones establecidas en los códigos procesales.

\footnotetext{
1 Juez de la Séptima Cámara del Trabajo de Mendoza. Especialista en Derecho Laboral (U. N. Cuyo y UN Litoral). Profesora de Derecho del Trabajo de grado y posgrado (Universidad Mendoza y UNCuyo). Autora de artículos y trabajos de la especialidad en obras colectivas e individuales. ORCID: https://orcid.org/0000-0002-8490-1134.E-mail: amsalas9295@gmail.com
} 
La caducidad en esos términos no resulta ajena al derecho laboral. Por el contrario, ha sido objeto de expresa regulación en diversas disposiciones, como es el caso de la LCT en cuyo art. 67 la establece para los supuestos de impugnación de medidas disciplinarias; art. 157 donde está prevista para los casos en que se omitiera la comunicación de la fecha de otorgamiento de las vacaciones anuales ordinarias; art. 200 establecida en relación a la adaptación ambiental del lugar de trabajo a los fines de calificar las tareas o condiciones del lugar; art 207, prevista para los casos de francos compensatorios; arts. 214, 215 y 217 , determinada para el supuesto de reincorporación de los trabajadores cuyos contratos fueron suspendidos por razones de convocatoria al servicio militar, desempeño de cargos electivos ya sea de orden político o representativos en asociaciones sindicales o en organismos que requieran representación sindical; entre muchos otros más.

También la encontramos receptada en algunos estatutos profesionales como el de viajante de comercio (ley 14.546) respecto de la aceptación de la nota de venta cuando la misma no es objeto de rechazo expreso por el empleador (art. 5); o en el de trabajadores de la construcción (ley 22.250) respecto de la percepción del fondo de desempleo (arts. 20 y 24). Además de leyes específicas como es el caso de la Ley Nacional de Empleo (ley 24.013) donde se admite el instituto respecto al derecho de percibir la sanción establecida en los arts. 8, 9 y 10, cuando no se cursa el emplazamiento establecido en el art. 11 en los términos y condiciones en él establecido.

Cabe tener presente que LCT claramente determina en el art. 259 que "....no hay otros modos de caducidad que los que resultan de esta ley...".

Pero en los aspectos no reglamentados será necesario recurrir a la regulación que sobre la materia contiene el Código Civil a condición de que resulten compatibles con los principios generales del Derecho del Trabajo.

Es que la caducidad no es un instituto propio del derecho laboral, sino que tiene raigambre civil. ${ }^{2}$ Por ello resulta de interés realizar un somero estudio de la regulación efectuada en el ámbito del CCyCom. luego de su modificación por ley 26.994. Y aquí nos encontramos con el "novedoso" tratamiento de la caducidad en los arts. 2566 al 2572, correspondientes al Título I del Libro Sexto.

Afirmamos que es una innovación normativa porque el Código de Vélez no contenía ninguna norma que regulara la caducidad con alcance general, aún luego de la reforma del año 1968. No se tuvo en cuenta la sistematización que el Código italiano de 1942 realizó en el capítulo referido a la "decadenza" y ello obligó a un esfuerzo por parte de la doctrina y jurisprudencia que permitió diseñar el instituto en las condiciones de su vigencia actual.

\section{II.- La caducidad en el Código Civil y Comercial}

El CCyCom. trata el instituto en forma genérica y con alcance universal. Ello es así porque la reforma introducida por la ley 26.994 tuvo por objeto la adecuación conceptual y metodológica a lo que el derecho de la época reclama. En ese entendimiento las normas contienen principios que permiten la flexibilización de su interpretación y aplicación en

\footnotetext{
2 MADDALONI, Osvaldo A. y TULA, Diego Javier: "Breves anotaciones sobre la prescripción y la caducidad en el Código Civil y Comercial y su impacto en el Derecho del trabajo", Cita: RC D 997/2017. Tomo: 2015 2, El Código Civil y Comercial de la Nación y el Derecho del Trabajo y de la Seguridad Social I. Revista de Derecho Laboral.
} 
función de los cambios sociales que el devenir de los tiempos produce. ${ }^{3}$

Es decir que se evitaron las soluciones casuísticas lo que lleva a que, ante la ausencia de regulación específica, será el juez quien deberá definir el caso concreto conforme los lineamientos legales, constitucionales y los establecidos por los tratados internacionales, especialmente aquellos que fueron incorporados en el art. 75, inc.22 de la CN luego de la reforma constitucional del año 1994.

Lo expuesto pone en evidencia el desafío que importa para la doctrina y jurisprudencia quienes, en la práctica, asumirán el trabajo de delinear la interpretación y aplicación del instituto a las situaciones que en concreto se presenten, respondiendo a las exigencias de los nuevos tiempos en el marco legal indicado.

\section{a- Lineamientos generales}

La lectura de la sistematización de la temática efectuada en el CCyCom. permite sintéticamente definirla y caracterizarla, así como diferenciarla de la prescripción, donde el tiempo también pasa a ser un elemento clave del derecho en juego.

En primer lugar se observa, como ya afirmamos, que el CCyCom. regula la caducidad en términos genéricos, por lo que su aplicación se concreta en los supuestos particulares de ciertos derechos en los que expresamente se recepta. En cambio, la prescripción presenta una mayor vocación de generalidad.

Por otra parte en la regulación de la caducidad se observa una distinción esencial, según se encuentren en juego derechos disponibles o no.

Si el plazo de caducidad se refiere a derechos sustanciales que son de orden público - y por tanto no disponibles-, el plazo de caducidad no puede ser modificado por las partes ni tampoco se admite su renuncia. En este caso los efectos de la caducidad son inalterables, no se suspenden ni interrumpen salvo disposición expresa de la ley (art. 2567). ${ }^{4}$

Cuando está en juego el orden público, la característica del plazo es su fatalidad, por ello la diligencia o prueba de falta de negligencia por parte del interesado no tiene incidencia si el plazo establecido se cumplió.

Esto nos lleva a concluir que, a diferencia de la prescripción, la dispensa no pude ser invocada.

Al estar en juego normas de orden público queda imposibilitada una hermenéutica extensiva o analógica. ${ }^{5}$

Por el contrario, si se trata de derechos disponibles las partes pueden libremente renunciar al plazo de caducidad (art. 2571) y pueden también pactarlos en las condiciones que

\footnotetext{
3 ÓSSOLA, Federico A "Prescripción y caducidad en el Código Civil y Comercial de la Nación. Aplicación de la ley en el tiempo". Cita: RC d 841/2017, Tomo: 2015-1 Prescripción. Aplicación del código civil y comercial a las situaciones preexistentes. Revista de derecho privado y comunitario. Rubinzal Culzoni.

4 Un ejemplo lo constituye el art. 16 de la Ley de Defensa del Consumidor. En esta ley al tratar el plazo de garantía se establece que ".... El tiempo durante el cual el consumidor está privado del uso de la cosa en garantía, por cualquier causa relacionada con su reparación, debe computarse como prolongación del plazo de garantía legal...".

5 HERNÁNDEZ, Carlos A "El plazo de garantía y caducidad del artículo 1646 del código civil. alcances y antecedentes históricos". Cita: RC D 2753/2012 Tomo: 20042 Responsabilidad de los profesionales de la construcción. Revista de Derecho de Daños
} 
determina el art. 2568 del CCyCom., es decir, siempre y cuando no torne excesivamente difícil el cumplimiento del plazo por la parte que le afecte y no se burlen disposiciones legales relativas a la prescripción.

En este caso funciona como impedimento de la caducidad el cumplimiento del acto previsto por la ley o por el acto jurídico y el reconocimiento del derecho realizado por la persona contra la cual se pretende hacer valer la caducidad prevista en un acto jurídico o en una norma relativa a derechos disponibles (art. 2569).

Consecuentemente, tratándose de derechos disponibles, el origen de la caducidad puede ser tanto legal como convencional.

En el tema se ha sostenido que las partes signatarias de convenios colectivos podrían concertar plazos de caducidad con el objeto de ordenar y facilitar el desarrollo de ciertos procedimientos necesarios para garantizar el goce de los derechos que el mismo convenio colectivo reconoce a los trabajadores, siempre que no hagan referencia a derechos irrenunciables del trabajador. ${ }^{6}$

Tanto la caducidad como la prescripción se caracterizan porque a través de ellos se busca otorgar certeza o seguridad jurídica a las relaciones jurídicas después de trascurrido el tiempo establecido. Se intenta impedir que los conflictos de mantengan en forma indefinida en el tiempo.

Pero se diferencia de la prescripción porque la finalidad de la decadencia o caducidad es la confirmación de los emplazamientos, mientras que en la prescripción extintiva es liberar al obligado.?

La prescripción extingue la acción pero deja subsistente la obligación en términos éticos o naturales. En este caso la intangibilidad del derecho se mantiene; sólo se priva a su titular de reclamarlo por no haberlo ejercido en el plazo establecido. Mientras que la caducidad determina el fenecimiento o extinción del derecho mismo y consecuentemente también de la acción que se derivada del él (art. 2566).

Esta distinción, lejos de responder a un purismo terminológico, acarrea importantes consecuencias de carácter práctico, tal como que la caducidad puede ser declarada de oficio por el juez mientras que la prescripción no (art. 2552 del CCyCom.), a excepción de aquellos derechos que sean disponibles.

Otra diferencia entre los dos institutos es el plazo. El mismo es más reducido en la caducidad que en la prescripción.

No obstante ello, se relacionan entre sí porque el derecho afectado a un plazo de caducidad no impide la aplicación de los plazos de prescripción que podría surgir en forma sobreviniente, como por ejemplo cuando la acción intentada fuera rechazada por un planteo de incompetencia, sin que se inste la acción ante el Tribunal competente (art. 2570)

6 MADALONI, Osvaldo A. y TULA, Diego Javier, Prescripción y caducidad en el Derecho del Trabajo, p. 164.

7 DÍAZ DE GUIJARRO, Enrique, "Tratado de Derecho de Familia", Tea, Bs. As., 1953, T.I, Nº 320, p. 444, citado KEMELMAJER DE CARLUCCI, Aída en "Prescripción y caducidad en el Derecho de Familia" Cita: RC D 2915/2012 Tomo: 1999 22, Prescripción liberatoria. Revista de Derecho Privado y Comunitario. 


\section{b.- Una primera conclusión}

La omisión de actuar en el plazo de caducidad establecido puede generar la presunción de la falta de necesidad del interesado. ${ }^{8}$

Ello lleva a realizar un esfuerzo a nivel doctrinal y jurisprudencial cuando se encuentran en juego derechos humanos fundamentales y la necesidad de tener en cuenta que siempre se trata de un instituto que es de carácter excepcional y de aplicación restrictiva.

Dado que el plazo de caducidad ataca el derecho mismo y no la acción, por lo menos el plazo de caducidad no debería ser más letal que el plazo de prescripción.

En modo especial debe tenerse en cuenta que, cuando está en juego la protección del derecho a la salud del trabajador, nos encontramos con un derecho fundamental que tiene amparo, como derecho autónomo, en el art.26 de la Convención Americana sobre Derechos Humanos.

Es que el derecho a la salud se vincula estrechamente con el derecho a la vida, y sobre todo a una vida sana, productiva y digna. Consecuentemente los desafíos que se presenten deben ser abordados con perspectiva de derechos humanos y respetando las obligaciones internacionales asumidas.

\section{III.- La caducidad en las leyes provinciales de adhesión a la ley $\mathbf{2 7 . 3 4 8}$}

A través de art. 4 de la llamada ley "complementaria de la Ley sobre Riesgos del Trabajo" $n^{\circ} 27.348$ se invitó a las provincias y a la Ciudad Autónoma de Buenos Aires a adherir al Título I. Este Título estableció la intervención de las comisiones médicas jurisdiccionales con carácter obligatorio y excluyente, a la que debe concurrir el trabajador, con el debido patrocinio letrado, a fin de definir el carácter profesional de su enfermedad o contingencia, la determinación de su incapacidad y las correspondientes prestaciones dinerarias previstas en la Ley de Riesgos del Trabajo.

La adhesión a esta instancia previa no sólo importó la delegación expresa a la jurisdicción administrativa nacional de la totalidad de las competencias necesarias para dar cumplimiento a la actuación de las comisiones médicas jurisdiccionales en los términos indicados, sino también la adecuación de la normativa local necesaria por parte de los Estados provinciales adherentes.

En respuesta a esa invitación algunas provincias dictaron las correspondientes leyes de adhesión con la particularidad de establecer, salvo el caso de la Ciudad Autónoma de Buenos Aires, las provincias de Neuquén y Buenos Aires, plazos de caducidad en distinta extensión, conforme el siguiente detalle:

\begin{tabular}{|l|l|l|l|l|}
\hline JURISDICCIÓN & NORMA & ART. & \multicolumn{2}{|l|}{ DIAS } \\
\hline C.A.B.A. & 5946 & 1 & \multicolumn{2}{|c|}{ No fija plazo } \\
\hline Córdoba & 10.456 & 3 & 45 & hábiles judiciales \\
\hline Mendoza & 9017 & 3 & 45 & hábiles judiciales \\
\hline Río Negro & 5253 & 7 & 60 & hábiles judiciales \\
\hline
\end{tabular}




\begin{tabular}{|l|l|l|l|l|}
\hline Corrientes & 6429 & 3 & 45 & hábiles judiciales \\
\hline Jujuy & 6056 & 8 & \multicolumn{2}{|c|}{$\begin{array}{l}\text { Prescripción de ley } \\
\text { de fondo }\end{array}$} \\
\hline Tierra del Fuego & 1199 & 3 & 20 & hábiles judiciales \\
\hline San Juan & 1709 & 3 & 30 & hábiles judiciales \\
\hline Entre Ríos & 10.532 & 5 & 15 & hábiles judiciales \\
\hline Misiones & $\begin{array}{l}\text { VII-86 } \\
\text { Dec.117/18 }\end{array}$ & 3 & 60 & hábiles judiciales \\
\hline Formosa & 1664 & 3 & 90 & hábiles judiciales \\
\hline Salta & 8086 & 80 & 45 & hábiles judiciales \\
\hline Chaco & 2856 & 3 & 45 & hábiles judiciales \\
\hline Neuquén & 3141 & 6 & \multicolumn{2}{|c|}{ No fija plazo } \\
\hline Buenos Aires & 14997 & 1 & \multicolumn{2}{|c|}{ No fija plazo }
\end{tabular}

Resulta cuanto menos llamativo el avance provincial en la temática dado que la adhesión requerida en el art. 4 de la ley 27.348, sólo se refería al Título I, y en modo alguno en el mismo se establecía un plazo de caducidad.

Dicho en otros términos, no se entiende por qué si en la ley nacional no se estableció un plazo de caducidad, sí lo determinaron la mayoría de las provincias que adhirieron a la ley nacional.

La normativa en cuestión ha generado reacción en el ámbito doctrinal y jurisprudencial en resistencia a su aplicación.

\section{IV.- Argumentos que ponen en crisis los plazos de caducidad de las legislaciones provinciales}

Los mismos se dirigen a cuestionar su valor constitucional y convencional. ${ }^{9}$

\section{a.- Valor constitucional}

En este caso fundamentalmente se afirma que las leyes en cuestión resultan inconstitucionales por contravenir la disposición contenida en el art. 75, inc. 12 de la CN.

Los Estados provinciales carecen de facultades para restringir temporalmente el ejercicio de los derechos sustanciales cuya regulación corresponde con exclusividad a la Nación. La única excepción admitida es cuando se regulan derechos en el ámbito del Derecho Público Provincial, como sería el caso de las leyes que rigen en materia de empleo público provincial.

En sentido contrario se ha afirmado que no existe apartamiento constitucional por parte de las provincias cuando regulan en materia de caducidad. Consideran que se trata de plazos de caducidad procesal, lo que constituye materia no delegada a la Nación.

\footnotetext{
9 Ver Suprema Corte de Justicia de Mendoza en autos $N^{\circ}$ 13-04393862-7/1, caratulados: "Herrera Walter Ariel en J: 159.114 Herrera Walter Ariel c/ Provincia A.R.T. SA p/ Accidente p/ REP" de fecha 29/09/2020- voto minoritario-; No 13-04763017-1/1, caratulados: "Cáceres Emilio Lucas Gabriel en J: 159.729 Cáceres Emilio Lucas Gabriel c/ Provincia ART S.A. p/ Accidente p/ REP” del 06/10/2020 -voto en mayoría- y autos N 13-04643220-1/1, caratulado: “Lencinas, Droguett Gaston Nicolás en J: 159539 “Lencinas Droguett Gastón Nicolás c/ Provincia ART p/Accidente p/ REP." del 06/11/2020) -voto en mayoría-.También TULA, Diego, "Accidentes de trabajo. Caducidad. Declaración de inconstitucionalidad. Facultades no delegadas. Federalismo, Revista Temas de Derecho Laboral y de la Seguridad Social. Erreius. Junio 2021, p. 499.
} 
Expresamente se ha sostenido que atento en la naturaleza procesal de dicha regulación, deviene como lógica consecuencia que el vencimiento del plazo previsto por la norma adjetiva no extingue el derecho sustancial sino una facultad procesal consistente en articular la impugnación del dictamen de la comisión médica.

Por tanto cada provincia puede ejercer el control judicial de la actividad administrativa estatal y establecer al respecto las consecuencias que acarrea el cumplimiento o incumplimiento en tiempo propio de actos procesales ${ }^{10}$

Cabe recordar que el art. 2532 del CCyCom. establece que las legislaciones locales podrían regular la prescripción liberatoria en materia tributaria. Debe entenderse que se refiere al ordenamiento tributario local.

En igual sentido el art. 2560 del CCyCom. determina que el plazo de prescripción es de cinco años, excepto que esté previsto uno diferente en la legislación local.

La autorización que el CCyCom. determina a favor de las provincias para legislar en materia de prescripción de derechos sustanciales resultaría aplicable al instituto de la caducidad.

Pero ese avance provincial ha sido resistido por la doctrina que acusa la inconstitucionalidad tanto del art. 2532 como del agregado introducido por la Comisión Bicameral al art. 2560. ${ }^{11}$

En igual sentido y respecto a la perspectiva tributaria la CSJN ha mantenido la doctrina referida a la inobjetable facultad de las provincias para darse leyes y ordenanzas de impuestos locales, y en general todas las que juzguen conducentes a sus bienes y prosperidad, sin más limitaciones que las emanadas del art. 108 de la Constitución (Fallos 7:373); siendo la creación de tributos en todas sus especies, la elección de hechos imponibles como hipótesis de incidencia tributaria y las formalidades de percepción, de resorte exclusivo de las provincias, cuyas facultades son amplias y discrecionales. De este modo, el criterio de oportunidad o de acierto con que la ejerzan no es cuestión revisable por cualquier otro poder (Fallos 51:350, 105:273, 114:262, 137:212, 150:419, 174:353), ya que es esencial a la autonomía de las provincias, la facultad de imponer contribuciones y percibirlas sin intervención alguna de autoridad extraña (Fallos 114:282). ${ }^{12}$

Pero también ha aclarado que la regulación de los aspectos sustanciales de las relaciones entre acreedores y deudores corresponde a la legislación nacional, por lo que no cabe a las provincias dictar leyes incompatibles con lo que los códigos de fondo establecen al respecto, ya que, al haber delegado en la Nación la facultad de dictarlos, han debido admitir la prevalencia de las leyes del Congreso y la necesaria limitación de no dictar normas que las contradigan (doctrina de Fallos: 176:115, 226:727, 235:571, 275:254, 311:1795 y los citados en éste, entre otros). Y que la facultad del Congreso Nacional para

\footnotetext{
10 Conf. "Guarnera, Miriam Gabriela c/ Experta ART", Fiscalía de Cámara Civil, Comercial y Laboral. Sala 7- Sec. 13 de la Cámara del Trabajo. Córdoba 22-10-19. También voto en minoría CNAT, Sec. 13 Sala VII.

11 Sobre el tema ver: ÁBALOS, María Gabriela "¿El fin de la doctrina Filcrosa? A propósito de la sanción del Nuevo Código Civil y Comercial de la Nación", en L. L. del 31-03-2015, Supl. Const., marzo de 2015, p. 6; SALAS, Luis M., "La prescripción de tributos provinciales y municipales y el Código Civil y Comercial", en L. L. Online, AR/DOC/3711/2014; SOLER, Osvaldo H., "Prescripción de la acción del fisco con relación a obligaciones tributarias", en L.L. Online, AR/DOC/1478/2013.

12 Colli, Hernán A y Dufourc, Benjamín "El nuevo Código Civil y Comercial y la prescripción liberatoria en materia de tributos locales" elDial.com DC2552 publicado el 12-06-18.
} 
dictar tales códigos comprende la de establecer las formalidades necesarias para hacer efectivos los derechos que reglamenta. ${ }^{13}$

Por ello se ha afirmado que los poderes constituidos no pueden arrogarse facultades propias del poder constituyente, alterando lo que éste ha determinado en la Constitución. Si conforme a ésta, a tenor de la doctrina de la Corte Suprema, del texto expreso del art. 75 inc.12 de la Constitución Nacional deriva la implícita pero inequívoca limitación provincial de regular la prescripción y los demás aspectos que se vinculan con la extinción de las acciones destinadas a hacer efectivos los derechos generados por las obligaciones de cualquier naturaleza, resulta írrita la legislación que importa desplazar la Constitución para delegar en los gobiernos locales facultades que la Carta Magna le ha asignado al Gobierno Federal."14

Lo expuesto resulta aplicable a las normas sobre caducidad establecida por las leyes provinciales supra individualizadas.

La inconstitucionalidad del plazo de caducidad establecido por las leyes provinciales se impone también en la medida en que se obstruye el control de la actividad jurisdiccional de la Comisión Médica Jurisdiccional por el Poder Judicial.

En nuestro país pacíficamente se ha aceptado que el legislador pueda atribuir competencia jurisdiccional a organismos o entes administrativos (CSJN Fallos: 247:646; 253:485; 301:1103) pero sujeto a diversas condiciones que limitan su ejercicio.

Los principios que rigen tal atribución es el de "excepcionalidad" y de "interpretación restrictiva".

La excepcionalidad es consecuencia de la regulación constitucional conforme la cual la función jurisdiccional es atribución del Poder Judicial (arts. 75 inc. 12, 109, 116 y 117 de la Constitución Nacional). Por lo tanto, los motivos tenidos en cuenta por el legislador para sustraer la materia de la jurisdicción de los jueces ordinarios deben estar razonablemente justificados pues, de lo contrario, la jurisdicción administrativa así creada carecería de sustento constitucional e importaría un avance indebido sobre las atribuciones que el art. 116 de la Constitución Nacional define como propias y exclusivas del Poder Judicial de la Nación. Es decir que la atribución de esa facultad debe hacerse a través de leyes dictadas por el congreso o legislatura provinciales y tal atribución debe realizarse en situaciones excepcionales que razonablemente lo justifique, lo que lleva a concluir que las leyes dictadas en estas condiciones son de interpretación restritiva (CSJN Fallos: 234:715; 290:237).

En cuanto a las condiciones que justifican la validez constitucional de la atribución de facultades jurisdiccionales a organismos administrativos podemos sintetizarlas en: 1- Ley especial que lo disponga; 2- Razonabilidad de la ley; 3- Imparcialidad del organismo que ejerza la función y 4- Revisión judicial posterior. (Conf. CSJN "Elena Fernández Arias y otros c/ José Poggio", Fallos 247:646 y autos n 750- 002119/96. A. 126. XXXVI. "Ángel Estrada y Cía. S.A. c/ Resol. 71/96 - Sec. Ener. y Puertos" de fecha 5 de abril de 2005).

13 CSJN, "Sandoval, Héctor c/Provincia del Neuquén", Fallos 320:1344. También en "Recurso de hecho deducido por Abel Alexis Latendorf (síndico) en la causa Filcrosa S.A. s/quiebra s/incidente de verificación de Municipalidad de Avellaneda” Fallos 326:3899, de fecha 30-09-03.

14 SPISSO, Rodolfo R. "Prescripción liberatoria de tributos provinciales en el Código Civil y Comercial" LL 01-12-2014, 1 • LL 2014-F , 1237. Cita Online: AR/DOC/4281/2014. 
El plazo de caducidad establecido por las leyes provinciales de adhesión impide el control judicial posterior y distrae del conocimiento judicial el debate que resulta de su incumbencia constitucional.

No podemos olvidar que la Carta Internacional Americana de Garantías Sociales conocida como Declaración de los Derechos Sociales del Trabajador de Bogotá de 1948, fruto de la Resolución XXIX de la $9^{\circ}$ Conferencia Interamericana, determinó que “... En cada Estado debe existir una jurisdicción especial de trabajo y un procedimiento adecuado para la rápida solución de conflictos..." (art. 36).

Los plazos de caducidad establecidos por las provincias burlan esa jurisdicción.

\section{b.- Valor convencional}

En una apretada síntesis las razones para cuestionar la validez de los plazos de caducidad en estudio serían los siguientes:

1.- Se viola el acceso a la justicia y tutela judicial: Este derecho humano fundamental se encuentra receptado en el art. 8 de La Declaración Universal de Derechos Humanos en cuanto establece que "... Toda persona tiene derecho a un recurso efectivo, ante los tribunales nacionales competentes, que la ampare contra actos que violen sus derechos fundamentales reconocidos por la constitución o por la ley...." .

En igual sentido se expide el art. 8 .1 -Garantías Judiciales- de la Convención Americana sobre Derechos Humanos -Pacto de San José de Costa Rica- al disponer que ".... Toda persona tiene derecho a ser oída, con las debidas garantías y dentro de un plazo razonable, por un juez o tribunal competente, independiente e imparcial, establecido con anterioridad por la ley, en la sustanciación de cualquier acusación penal formulada contra ella, o para la determinación de sus derechos y obligaciones de orden civil, laboral, fiscal o de cualquier otro carácter...".

Y también en su art. 25 -Protección Judicial- se establece que "...1. Toda persona tiene derecho a un recurso sencillo y rápido o a cualquier otro recurso efectivo ante los jueces o tribunales competentes, que la ampare contra actos que violen sus derechos fundamentales reconocidos por la Constitución, la ley o la presente Convención, aun cuando tal violación sea cometida por personas que actúen en ejercicio de sus funciones oficiales. 2. Los Estados Partes se comprometen: a) a garantizar que la autoridad competente prevista por el sistema legal del Estado decidirá sobre los derechos de toda persona que interponga tal recurso; b) a desarrollar las posibilidades de recurso judicial, y c) a garantizar el cumplimiento, por las autoridades competentes, de toda decisión en que se haya estimado procedente el recurso...".

De manera tal que los Estados tienen el deber de organizar el aparato gubernamental y las estructuras que sean capaces de asegurar jurídicamente el libre y pleno ejercicio de los derechos humanos. ${ }^{15}$

En forma clara las leyes provinciales indicadas violan estos convenios internacionales que integran el bloque constitucional previsto en el art. 75, inc. 22 de la CN.

15 CIDH, Caso "Velásquez Rodríguez Vs. Honduras", sentencia de fecha 29-07-88. Serie C n 4-165, Caso "Almonacid Arellano y otros Vs. Chile", sentencia 26-09-06. Serie C n 154-11; Caso "Contreras y otros Vs. El Salvador", sentencia 31-08-11, entre muchas otras. 
2.- Se viola la Convención sobre los Derechos de las Personas con Discapacidad -ratificado por ley 26.378- por la que se establece la necesidad de introducir adaptaciones y reforzar la protección para que las personas con discapacidad puedan ejercer de forma efectiva sus derechos a la salud, la educación, la accesibilidad y el trabajo.

3.- Se viola la Convención Interamericana para la Eliminación de Todas las Formas de Discriminación contra las Personas con Discapacidad -ratificado por ley 25.280-, por que el se insta a los países a adoptar "las medidas de carácter legislativo, social, educativo, laboral o de cualquier otra índole, necesarias para eliminar la discriminación contra las personas con discapacidad y propiciar su plena integración en la sociedad.

4.- Se viola "Las Reglas de Brasilia" donde se establece como beneficiarios a quienes se encuentran en condición de vulnerabilidad por razón de su edad, género, estado físico o mental, o por circunstancias sociales, económicas, étnicas y/o culturales, y que tienen especiales dificultades, e imponen a los magistrados diversos deberes tendientes a "promover las condiciones necesarias para que la tutela judicial de los derechos reconocidos por el ordenamiento sea efectiva, adoptando aquellas medidas que mejor se adapten a cada condición de vulnerabilidad (art. 25); revisar "las reglas de procedimiento para facilitar el acceso de las personas en condición de vulnerabilidad, adoptando aquellas medidas de organización y de gestión judicial que resulten conducentes a tal fin" (art. 33); y adoptar las "medidas necesarias para evitar retrasos en la tramitación de las causas, garantizando la pronta resolución judicial, así como una ejecución rápida de lo resuelto" (art. 38); impulsar formas alternativas de resolución de conflictos (art. 43), entre otras medidas que tienen por principal objetivo garantizar a las personas "el pleno goce de los servicios del sistema judicial" (art.1).

Se debe tener presente que los plazos de caducidad establecidos por las leyes provinciales de adhesión están destinados a aquellos sujetos que pretenden una decisión judicial que evalúe la decisión administrativa que cuestiona; es decir, trabajadores que gozan de preferente tutela constitucional (CSJN “Vizzoti, Carlos A. c. AMSA S.A.") y que además, sufren alguna incapacidad que merece ser reparada.

Por último también se deberá tener presente que desde la sentencia en el caso "Almonacid Arellano y otros Vs. Chile", la CIDH se ha pronunciado reiteradamente en el sentido que el Poder Judicial debe ejercer una especie de control de convencionalidad entre las normas jurídicas internas que aplican en los casos concretos y la Convención Americana sobre Derechos Humanos. En esta tarea el Poder Judicial debe tener en cuenta no sólo el Tratado, sino también la interpretación del mismo que ha hecho la Corte Interamericana, interprete última de la Convención Americana.

Más tarde, la Corte utilizó en varios casos un concepto más amplio exigiendo que el Poder Judicial ejerza un control de convencionalidad "ex officio" entre las normas internas y la Convención Americana. ${ }^{16}$

16 CIDH "Almonacid Arellano y otros versus Chile", sentencia del 26-09-06. Serie nº 154-124; Caso "Trabajadores Cesanteados del Congreso (Aguado Alfaro y otros) Vs. Perú", sentencia 24-11-06 Serie C, n 158-128; Caso "Radilla Pacheco Vs. México", sentencia 23-11-09, Serie C, No 209-339; Caso "Ibsen Cárdenas e Ibsen Peña Vs. Bolivia”, sentencia 01-09-10, Serie C, No 217-202; Caso “Gelman Vs. Uruguay", sentencia 24-02-11. Serie C n 221-193; Caso "Mendoza y otros Vs. Argentina", sentencia 14-05-13, Serie C n 260-221, entre muchas otras.

En igual sentido CSJN, "Rodríguez Pereyra, Jorge Luis y otra c/ Ejército Argentino s/ Daños y Perjuicios", 27-11-12. 


\section{V.- La conclusión final que genera el tema}

Los plazos de caducidad establecidos por las leyes provinciales de adhesión a la ley 27.348 cuanto menos representa una regresión en la legislación laboral.

Ni la legislación existente en la materia con anterioridad al dictado de la ley 27.348 ni en esta misma ley se han establecidos plazos de caducidad.

La Comisión Interamericana ha considerado que para evaluar si una medida regresiva es compatible con la Convención Americana, se deberá "determinar si se encuentra justificada por razones de suficiente peso". ${ }^{17}$ Situación que no se observa en el tema analizado.

La dimensión progresiva de protección de los Derechos Humanos incluye un sentido de progreso que requiere la mejora efectiva de las condiciones de goce y ejercicio de estos derechos.

Las leyes provinciales citadas, lejos de implementar acciones para lograr la protección integral de los derechos de los trabajadores que han sufrido un daño en su integridad personal, los sanciona con la pérdida total del derecho que le asiste que no es otro que el de lograr la plena efectividad del derecho a la salud y la reparación adecuada de las incapacidades sufridas.

También en la práctica se produce una discriminación injustificada en dos aspectos:

Uno referido a los trabajadores vinculados por relaciones laborales no registradas con empleadores alcanzados por el régimen de riesgos de trabajo (art. 1 de la ley 27.348) quienes gozan de una plena garantía judicial o tutela judicial efectiva en desmedro de aquellos que se encuentran en relaciones laborales legalmente formalizadas.

Y otro referido a la falta de adhesión por un número importante de provincias, como es el caso de Chubut, Santa Cruz, San Luis, La Pampa, La Rioja, Tucumán, entre muchas otras. Ello determina una desventajosa e injustificada situación peyorativa para de los trabajadores de las provincias que sí adhirieron, por la flagrante violación del derecho de igualdad ante la ley que prescribe el art. 16 de la CN y la prohibición de discriminación que establece el art. 17 de la LCT .

La misma situación se produce respecto de las provincias que adhirieron a la ley 27.348 pero sin establecer plazos de caducidad, como es el caso de las provincias de Neuquén, Buenos Aires, Jujuy y Ciudad Autónoma de Buenos Aires.

Todo ello sin perjuicio de la inexplicable variedad de plazos establecidos en forma disímil por cada provincia.

Sin duda que la temática abordada presenta planteos que motiva debates relevantes que exceden el puntual análisis efectuado. Ése es el motivo que invita a redoblar el esfuerzo en la búsqueda de soluciones que haga que la protección laboral

17 CIDH Caso "Acevedo Buendía y otros ("Cesantes y Jubilados de la Contraloría”) Vs. Perú", sentencia de fecha 01-07-09. Serie C No. 198, párr. 103, Informe de Admisibilidad y Fondo No. 38/09, Caso 12.670, "Asociación Nacional de Ex Servidores del Instituto Peruano de Seguridad Social y Otras Vs. Perú", emitido por la Comisión Interamericana de Derechos Humanos en fecha 27-03-09, párrs. 140 a 147. 